\title{
Juvenile osteopetrosis: effects on blood and bone of prednisone and a low calcium, high phosphate diet
}

\author{
L M DORANTES, A M MEJIA, AND S DORANTES \\ Endocrine and Hematology Departments, Hospital Infantil de Mexico, Mexico City
}

SUMMARY Four children with juvenile osteopetrosis are described who were treated with a combination of prednisone and a low calcium, high phosphate diet.

One of the children, treated as a neonate, achieved complete clinical and radiological remission from the disease after nine months, at which point treatment was stopped. There have been no signs of recurrence for two years. Two who did not start treatment until over 24 months of age have shown a good clinical and radiological response but have remained on treatment for six years. The fourth child started treatment at 6 months and showed a good clinical response, but $x$ ray films showed no change nine months later. He was then lost to follow up, stopped treatment, and died two years later of a septicaemia.

These patients provide further evidence for the efficacy of steroids in juvenile osteopetrosis, and the combination with the low calcium, high phosphate diet described offers a potentially effective alternative treatment to marrow transplantation, both for the haematological and skeletal complications of the disorder.

Juvenile osteopetrosis, or Albers-Schönberg disease, is a rare, autosomal, recessive, inherited disorder. ${ }^{1}$ It is characterised by an increase in bone density, ${ }^{2}$ which leads to neurological abnormalities such as blindness, deafness, and facial palsy due to narrowing of cranial foramina and compression of cranial nerves and to haematological abnormalities such as anaemia, thrombocytopenia, and leucopenia . Related infection and bleeding are common causes of early death. ${ }^{13-5}$

The cause remains uncertain, but diminished osteoclast activity with deficient bone resorption has been described in patients with juvenile osteopetrosis, ${ }^{6-8}$ and in osteopetrotic rats osteoclast activity increases after infusion with mononuclear cells from either the spleen or the thymus of normal litter mates. ${ }^{910}$

Until recently, treatment for juvenile osteopetrosis was symptomatic and consisted merely of blood transfusions, splenectomy, and surgical decompression of affected cranial nerves. Good results have been described with bone marrow transplantation with return of blood cell production and osteoclastic resorption, ${ }^{11} 12$ but in one patient relapse of the disease process was observed 13 months after transplantation.

Prednisone has also been reported to have an effect on haemopoietic tissue and calcium metabolism in osteopetrotic children, without the inherent dangers of transplantation. ${ }^{13}$

We record here our experience with four children who were treated with prednisone, together with a low calcium diet and oral phosphate supplements.

\section{Case reports}

All four patients were born from non-consanguineous marriages and had a negative family history with normal bone $x$ ray films of parents and siblings. The age, weight, and height of the patients are shown in Table $1 . X$ ray films taken of the patients before treatment showed a generalised increase of bone density; three radiologists considered the radiographic changes to be characteristic of osteopetrosis. Narrowed optic foramina and compression of the optic and auditory nerves were observed in two of the patients.

All of them developed a leucoerythroblastic anaemia and thrombocytopenia and required blood transfusions. Hepatomegaly and splenomegaly were present in all four. Bone marrow biopsy specimens showed hypermineralisation and virtual obliteration of the medullary spaces with rare and small haematopoietic foci. The four children were placed on a 
Table 1 Height and weight values before and after treatment in the four cases

\begin{tabular}{|c|c|c|c|c|c|c|c|c|c|c|c|c|c|c|}
\hline \multirow[t]{3}{*}{ Case No } & \multicolumn{7}{|c|}{ Before treatment } & \multicolumn{7}{|c|}{ After treatment } \\
\hline & \multirow{2}{*}{$\begin{array}{l}\text { Age } \\
\text { (yrs) }\end{array}$} & \multicolumn{3}{|c|}{ Height } & \multicolumn{3}{|c|}{ Weight } & \multirow{2}{*}{$\begin{array}{l}\text { Age } \\
\text { (yrs) }\end{array}$} & \multicolumn{3}{|c|}{ Height } & \multicolumn{3}{|c|}{ Weight } \\
\hline & & $(\mathrm{cm})$ & $50 t h$ & $3 r d$ & $(k g)$ & S0th & $3 r d$ & & $(\mathrm{~cm})$ & $50 t h$ & $3 r d$ & $(k g)$ & $50 t h$ & $3 r d$ \\
\hline 1 & $2 \cdot 3$ & $86 \cdot 0$ & 83.4 & $78 \cdot 4$ & 11.4 & $11 \cdot 7$ & $10 \cdot 2$ & $6 \cdot 3$ & 105 & 115 & 106 & 18.9 & $21 \cdot 4$ & $17 \cdot 6$ \\
\hline 3 & 0.1 & $45 \cdot 0$ & $54 \cdot 3$ & $50 \cdot 2$ & $2 \cdot 6$ & 4.4 & $3 \cdot 3$ & 1.8 & 81 & $82 \cdot 8$ & 78 & 11 & $11 \cdot 6$ & $10 \cdot 1$ \\
\hline 4 & 0.5 & $59 \cdot 0$ & 67.9 & $63 \cdot 6$ & 5.9 & $7 \cdot 8$ & $6 \cdot 5$ & 1.5 & 63 & $80 \cdot 8$ & 76 & 10 & $11 \cdot 2$ & 9.7 \\
\hline
\end{tabular}

Table 2 Haemoglobin concentrations and neutrophil and platelet counts obtained before and after treatment

\begin{tabular}{|c|c|c|c|c|c|c|}
\hline \multirow[t]{2}{*}{$\begin{array}{l}\text { Case } \\
\text { No }\end{array}$} & \multicolumn{2}{|c|}{$\begin{array}{l}\text { Haemoglobin } \\
(\mathrm{g} / \mathrm{dl})\end{array}$} & \multicolumn{2}{|c|}{$\begin{array}{l}\text { Neutrophils } \\
\left(\begin{array}{ll}x & \left.10^{9} / l\right)\end{array}\right.\end{array}$} & \multicolumn{2}{|c|}{$\begin{array}{l}\text { Platelets } \\
\left(\begin{array}{ll}x & \left.10^{9} / l\right)\end{array}\right.\end{array}$} \\
\hline & Before & After & Before & After & Before & After \\
\hline 1 & $9 \cdot 0$ & $13 \cdot 0$ & $2 \cdot 0$ & $7 \cdot 0$ & 100 & 300 \\
\hline 2 & $6 \cdot 5$ & $11 \cdot 5$ & $2 \cdot 5$ & $7 \cdot 5$ & 60 & 160 \\
\hline 3 & $8 \cdot 0$ & $12 \cdot 0$ & $1 \cdot 0$ & $6 \cdot 0$ & 42 & 300 \\
\hline 4 & $6 \cdot 0$ & $10 \cdot 5$ & $1 \cdot 5$ & $5 \cdot 0$ & 30 & 150 \\
\hline
\end{tabular}

treatment protocol consisting of oral prednisone 1 $\mathrm{mg} / \mathrm{kg} /$ day. The three older children also received a diet containing $400 \mathrm{mg}$ calcium each day made up of $350 \mathrm{ml}$ milk, about $140 \mathrm{~g}$ meat, one egg, and vegetables, together with fruit and cereal to meet caloric requirements. Some foods were omitted from the diet, like fish, cheese, beans, spinach, cabbage, and milk derivatives. The newborn baby was bottle fed and received a reduced amount of calcium in his diet that ranged between 150 and 350 $\mathrm{mg}$ each day during the treatment period. Oral phosphate $1 \mathrm{~g}$ each day was also added to the diet, divided in three doses from a solution containing $72 \cdot 5 \mathrm{~g}$ dibasic sodium phosphate $\left(\mathrm{Na}_{2} \mathrm{HPO}_{4} \cdot 7 \mathrm{H}_{2} \mathrm{O}\right)$, and $9.1 \mathrm{~g}$ monobasic sodium phosphate $(\mathrm{Na}$ $\mathrm{H}_{2} \mathrm{PO}_{4} \mathrm{H}_{2} \mathrm{O}$ ) in 1 litre of water. This provided 1100 $\mathrm{mg}$ of phosphorus for each $100 \mathrm{ml}$.

Case 1. This girl was diagnosed as having osteopetrosis at 4 months of age. In the subsequent two years she required three red cell transfusions due to anaemia. When she was 2 years old she was admitted to hospital because of development of nystagmus, exophthalmus, and partial loss of vision. There was a bilateral optical atrophy, more on the left than the right. She also had anaemia, leucopenia, and thrombocytopenia (Table 2). Her height and weight were normal (Table 1). She then began treatment with prednisone and a low calcium and high phosphate diet, which has been continued for six years.
Two months after treatment was begun a frontal craniotomy was carried out to free both optical nerves and resulted in an improvement of the vision of her right eye.

No blood transfusions were needed after treatment began and haemoglobin, leucocytes, and platelet counts have since consistently yielded normal results, and the hepatosplenomegaly has disappeared.

After two years of treatment $x$ ray films began to show a zone of bone resorption in the proximal half of the radius and ulna in both arms that has extended and currently occupies roughly half of the long bones in both arms (Fig. 1).

Her present physical appearance is shown in Figure 2. There has been a regression in the exophthalmus, and no complications of chronic

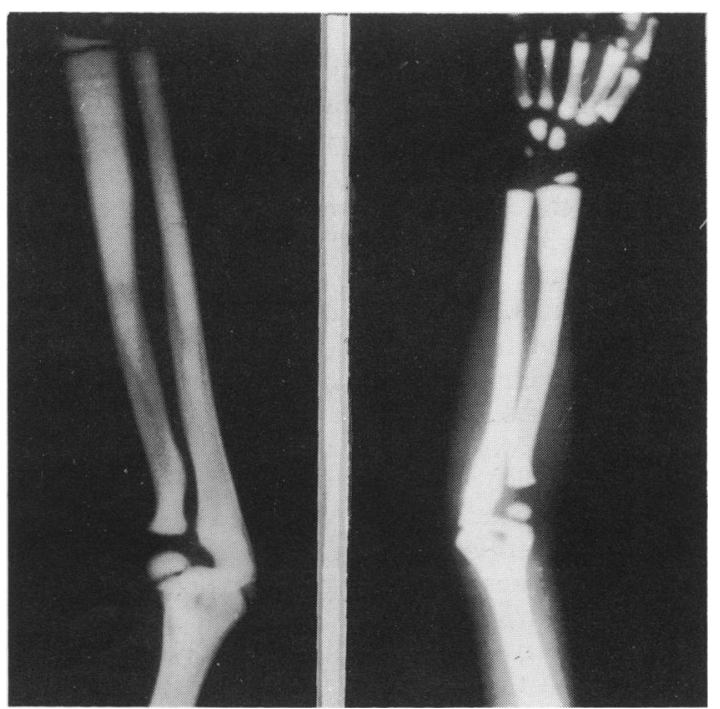

Fig. $1 \mathrm{X}$ ray films of arm of case 1 taken at 2 years of age before treatment (right), showing generalised increase of bone density, and at 6 years of age (left), showing demineralisation in the proximal half of radius and ulna. 

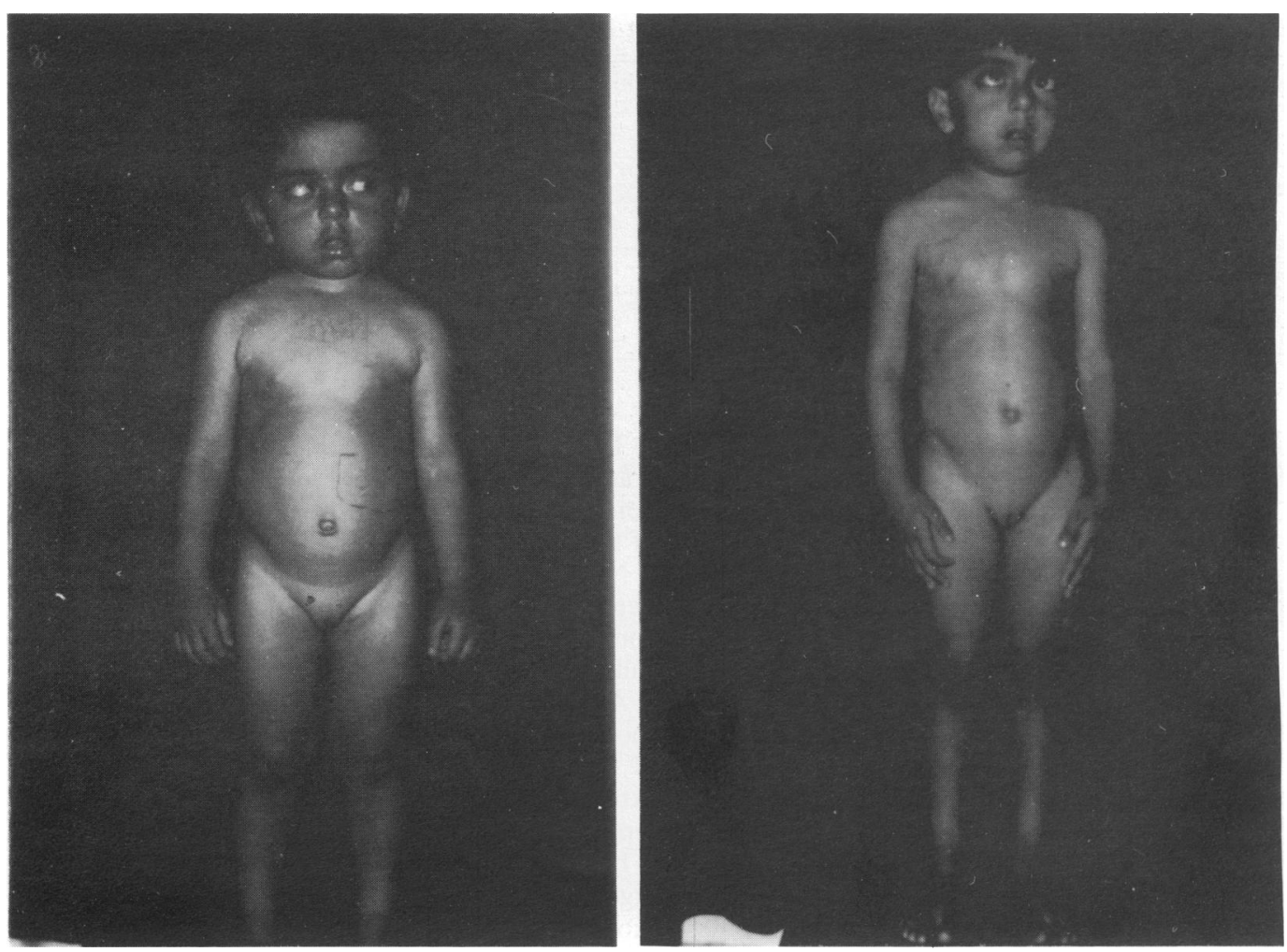

Fig. 2 Physical appearance of case 2 at 2 and 6 years of age. There are virtually no signs of Cushing's stigmata at age 6 despite the fact that she has received prednisone for four years.

administration of steroids, such as diabetes, hypertension, or frequent infection, have been detected.

The patient attends school regularly but not without certain difficulties due to her limited vision. Her growth rate has dropped from the 50th percentile to the 3 rd percentile (Table 1).

Case 2. This boy developed anaemia and recurrent infections at 6 months of age. Splenomegaly was also found. He was given 20 transfusions before he was 30 months. At that time he was admitted to our hospital and was found to have prominent parietal bones, jaundice, pallor, petechiae, and hepatosplenomegaly. A skeletal survey showed changes consistent with osteopetrosis. He also seemed to have an anaemia at least partially haemolytic and possibly due to an intrinsic red cell defect. His haemoglobin concentration was $8 \mathrm{~g} / \mathrm{dl}$, his reticulocyte count was $10.5 \%$, and the half life of his erythrocytes transfused into a normal person was 7.9 days. The haptoglobin concentration was $5 \mathrm{mg} / \mathrm{dl}$ and the plasma free haemoglobin concentration was 125 $\mathrm{mg} / \mathrm{dl}$.
Audiometry and the visual evaluation yielded normal results. He was placed on the treatment described above, on which he has remained for the past six years.

After six months blood transfusions were no longer required. A reduction of spleen size was also noted.

Currently, he is free of symptoms and attends school regularly. Apart from his plump physical appearance, moonface, and a slow growth rate (Table 1) no other complications of Cushing's syndrome are present. A decrease in density of the skull bones has been noted recently.

Case 3. This boy was born by caesarean section. He was admitted to our hospital two days after birth with pallor, jaundice, and poor response to stimuli. His liver was enlarged to $4 \mathrm{~cm}$ below the right costal margin and the spleen to $2 \mathrm{~cm}$ below the left costal margin. A radiological study showed skeletal features consistent with osteopetrosis (Fig. 3). The patient was placed on treatment with prednisone and reduced calcium and phosphate supplements. 


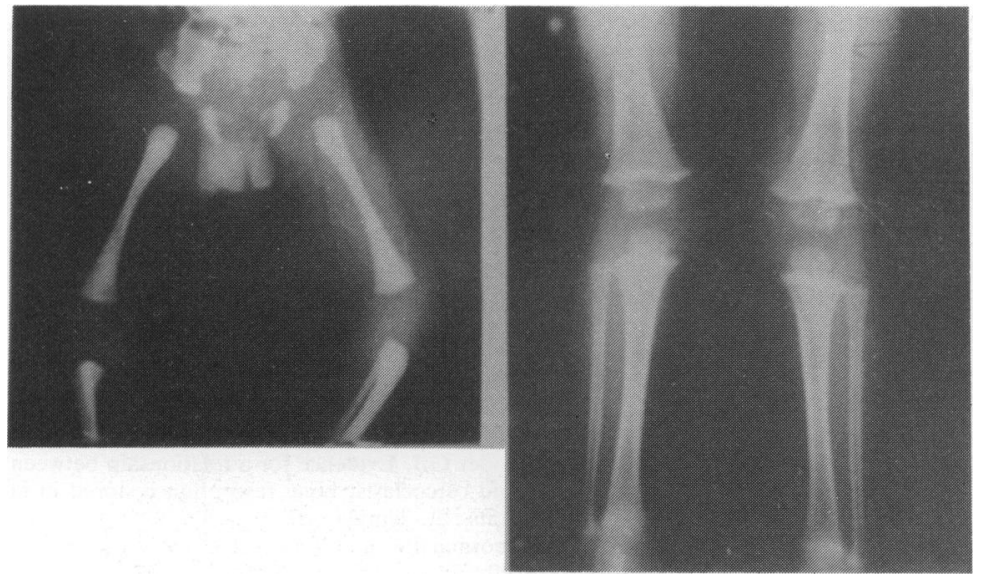

Fig. 3 X ray films of case 3 taken at 1 month of age (left), showing the typical appearance of osteopetrosis, and 1 year of age (right), showing a normal appearance.

After nine months, during which the child remained asymptomatic, a further radiological survey of the skeleton showed normal bone density with development of medullary spaces. Treatment was then stopped. After two years there has been no recurrence of disease.

Case 4. This boy presented with recurrent respiratory infections, gastroenteritis, and pyelonephritis during the first six months of his life. He also developed nystagmus, exophthalmus, and thrombocytopenia and required transfusion for anaemia.

He was admitted to our hospital when 6 months old. He was of short stature and low weight (Table 1). He also had hepatomegaly to $6 \mathrm{~cm}$ below the right costal margin, splenomegaly to $5 \mathrm{~cm}$ of the left costal margin, pallor, petechiae, and exophthalmus. There was partial bilateral optic atrophy and narrowed optic foramina. Audiometry showed bilateral deafness due to compression of the auditory nerves. A frontal craniotomy was performed to free the left optic nerve.

$\mathrm{He}$ was started on combined treatment with prednisone and low calcium and high phosphate diet, and for the next nine months remained asymptomatic and did not require transfusion. The splenomegaly decreased from $5 \mathrm{~cm}$ to $2 \mathrm{~cm}$. No changes in bone density were noted. At this point he was lost to follow up but two years later we were informed that he had died of a septicaemia, the treatment having been stopped one and a half years before his death.

\section{Discussion}

The diagnostic criteria for juvenile osteopetrosis are adequately fulfilled by all four of the described patients and radiologically they showed the classical picture of this disease. All of them showed some kind of haematological disturbance with liver and spleen enlargement, and all except the baby diagnosed in the neonatal period had at least one cranial nerve affected. Bone biopsy specimens showed hypermineralisation characteristic of osteopetrosis.

Children with this disorder usually have a short life of less than 3 years. ${ }^{4}$ Early death is generally produced by anaemia, bleeding due to thrombocytopenia, or infection secondary to neutropenia. Often compression of a cranial nerve causes blindness and deafness. In contrast to this, of the four children we describe three are alive, two have lived more than five years, and all are free from the above complications.

There have been no reports either in the untreated disease or during treatment with prednisone alone of convincing regression of osteosclerosis. Despite untreated patients showing radiological heterogeneity with different degrees of how much the bones are affected ${ }^{1}$ and despite the possibility that bone resorption might come and go spontaneously, ${ }^{15}$ radiographic changes of the degree we have observed in association with haematologic remission were not described in a recent review of the published reports. Impressive bone changes have been observed after bone marrow transplantation ${ }^{11} 12$ but were not maintained in one child who relapsed.

Against this background we think it is important to emphasise that in cases 1 and 3 there has been formation of marrow cavity and radiological improvement of the skull bones, with corresponding decrease of exophthalmus and better visual function in case 1. 
The changes in bone density could be explained by the well known osteoporotic effect of prednisone $^{16}$ together with an increase of the concentrations of parathyroid hormone that we found in our patients. This was possibly produced by the low dietary calcium and the phosphate mediated impairment of calcium absorption, in accordance with the findings of Glorieux et al, who induced bone resorption in patients with juvenile osteopetrosis by infusion of bovine parathyroid hormone. ${ }^{17}$

Improvement of the anaemia and thrombocytopenia in children with juvenile osteopetrosis has been noted before with prednisone. ${ }^{13}$ Our patients confirm this observation, all losing their dependency on transfusions.

In case 2 a haemolytic component to the anaemia was found, which seemed to be due to an intrinsic red cell defect. Shortened red cell survival of this nature has been described in juvenile osteopetrosis, but the reason for it is not clear.

The case of the neonate we describe who has had such rapid decrease in his hepatosplenomegaly and improvement both in bone density and haemoglobin concentration suggests that either he had a spontaneous remission, which has not been reported before, or that treatment begun early in life can induce a prolonged and complete remission of the disorder.

\footnotetext{
References

1 Horton WA, Schimke RN, Iyama T. Osteopetrosis: further heterogeneity. J Pediatr 1980;97:580-5.

2 Beighton P, Horan F, Hamersma H. A review of the osteopetrosis. Postgrad Med J 1977;53:507-15.

3 Ballesteros-Fernández JA, Gómez-Rivas B, Morey-Molina A, Palomar-Buil $M$, Señor de Uria C, Gómez Martínez JL. Osteopetrosis de Albers-Schönberg. Presentación de 2 casos familiares y revisión de la literatura. Rev Clin Esp 1976;142: 261-6.
}

${ }^{4}$ Loria-Cortés R, Quesada-Calvo E, Cordero-Chaverri C. Osteopetrosis in children. J Pediatr 1977;91:43-7.

${ }^{5}$ Horan FT, Beighton PH. Osteopetrosis in the Fairback collection. J Bone Joint Surg 1978;60:53-5.

${ }^{6}$ Reeves J, Arnaud S, Gordon S, et al. The pathogensis of infantile malignant osteopetrosis: bone mineral metabolism and complications in five infants. Metab Bone Dis Relat Res 1981;3:135-42.

7 Teitelbaum SL, Coccia PF, Brown DM, Kaun AJ. Malignant osteopetrosis: a disease of abnormal osteoclast proliferation. Metab Bone Dis Relat Res 1981;3:99-105.

${ }^{8}$ Bonucci E, Sartori E, Spina M. Osteopetrosis fetalis. Virchows Arch [Pathol Anat] 1975;368:109-13.

${ }^{9}$ Marks SC. Studies of the mechanism of spleen cell cure for osteopetrosis in ia rats: appearance of osteoclast with ruffled borders. Am J Anat 1978;151:119-30.

${ }^{10}$ Marks SC, Schneider GB. Evidence for a relationship between lymphoid cells and osteoclasts: bone resorption restored in ia (osteopetrotic) rats by lymphocytes, monocytes and macrophages from a normal littermate. Am J Anat 1978;152:331-42.

1 Ballet JJ, Griscelly C, Coutris C, Milhaud G, Maroteaus P. Bone marrow transplantation in osteopetrosis. Lancet 1977;ii:1137.

12 Sorell M, Kapoor N, Kirkpatrick D, et al. Marrow transplantation for juvenile osteopetrosis. Am J Med 1981;70:1280-7.

13 Reeves JD, Huffer WE, August CS, Hathaway WE, Koerper M, Walters CE. The hematopoietic effects of prednisone therapy in four infants with osteopetrosis. $J$ Pediatr 1979;94:210-1.

14 Ramos-Galvan R. Somatometria pediátrica. Estudio semilongitudinal en niños de la Ciudad de México. Arch Inv Med (Mex) 1975;6:(Suppl 1):83-396.

${ }^{15}$ Milgram JW, Jasty M. Osteopetrosis. A morphological study of twenty-one cases. J Bone Joint Surg 1982;64:912-29.

${ }^{16}$ Chesney RW, Mayess RB, Rose P, Jax DK. Effect of prednisone on growth and bone mineral content in childhood glomerular disease. Am J Dis Child 1978;132:768-72.

17 Glorieux FH, Pettifor JM, Marie PJ, Delvin EE, Travers R, Shepard $\mathrm{N}$. Induction of bone resorption by parathyroid hormone in congenital malignant osteopetrosis. Metab Bone Dis Relat Res 1981;3:143-50.

Correspondence to Dr L M Dorantes, Endocrine and Hematology Departments, Hospital Infantil de Mexico, Mexico City, Mexico.

Received 3 April 1986 